\title{
Peculiarities of Thermal Dissociation of Oxides during Submerged Arc Welding
}

\author{
(Peculiaridades da Dissociação Térmica de Óxidos durante Soldagem por Arco Submerso)
}

\author{
Leonid Zhdanov', Vladyslav Kovalenko', Nataliya Strelenko ${ }^{3}$, Yevgenia Chvertko ${ }^{4}$ \\ ${ }^{1}$ National Technical University of Ukraine "Kyiv Polytechnic Institute”, Kyiv, Ukraine, zv-zhdanov@yandex.ua \\ ${ }^{2}$ National Technical University of Ukraine "Kyiv Polytechnic Institute”, Kyiv, Ukraine, rdk@i.com.ua \\ ${ }^{3}$ National Technical University of Ukraine "Kyiv Polytechnic Institute”, Kyiv, Ukraine, strelenkon@rambler.ru \\ ${ }^{4}$ National Technical University of Ukraine "Kyiv Polytechnic Institute”, Kyiv, Ukraine, e.chvertko@kpi.ua
}

\begin{abstract}
Resumo
Um método para estabelecimento do processo de dissociação térmica dos óxidos na zona de reação durante soldagem e deposição por arco submerso é apresentado. Foram desenvolvidas equações não lineares combinadas para definição da composição da mistura gásvapor. Estas descrevem a dissociação dos óxidos do tipo $\mathrm{MeO}, \mathrm{MeO}_{2}$ e $\mathrm{Me}_{2} \mathrm{O}_{3}$. Cálculos dos processos de dissociação dos óxidos foram feitos para óxidos que são comumente incluídos em fluxos de soldagem. Os resultados e análises são apresentados. O método proposto parece ser adequado e aplicável para análises de processos durante operações a arco submerso as quais acontecem com fases gasosas.
\end{abstract}

Palavras-chave: soldagem por arco submerso, fase gasosa, dissociação térmica dos óxidos gasosos, cálculos termodinâmicos, mecanismos de dissociação

\begin{abstract}
A method of settlement of the process of thermal dissociation of oxides in reaction zone during the submerged arc welding and welding deposition is presented. Combined non-linear equations for definition of gas-vapour mixture composition were developed. They describe the dissociation of $\mathrm{MeO}, \mathrm{MeO}_{2}$ and $\mathrm{Me}_{2} \mathrm{O}_{3}$ types of oxides. Calculations of the processes of oxide dissociation were performed for the oxides that are commonly included into welding fluxes. Their results and analysis are presented. The method proposed appeared to be adequate and applicable for analysis of processes during submerged arc operation that run in the gas phase.
\end{abstract}

Key-words: submerged arc welding, gas phase, thermal dissociation of gaseous oxides, thermodynamic calculations, mechanism of dissociation

\section{Introduction}

The metallurgical processes run during the submerged arc welding (SAW) still remain unstudied from the point of view of physical and chemical interaction in the reaction zone. This is due to formal approach to the analysis of metallurgical reactions, which is performed for the slag-metal boundary zone only. As a result the classification of fluxes based on their basicity is commonly used in present time. This makes it impossible to calculate the oxygen content in the weld metal as well as that of alloying elements, silicon and manganese in the first place. Development of new fluxes is often based on empiric methods as a result of total ignorance of gas phase and reactions run on its boundaries.

During the submerged arc welding process, the reaction zone consists of three phases: metal; slag; and gas [1-4]. The gas phase is highly heated and experimental methods can be hardly applied for its analysis [2-4]. However, many researchers consider the gas phase to intensively influence the metallurgical

Recebido em 19/04/2013, texto final em 12/07/2013. processes in the reaction zone and the final chemical content of the weld metal $[2,4-6]$. The fact that these reactions are not taken into account in the results, a very low correlation is achieved between experimental data and calculation performed basing of the flux content and welding parameters. The reason is these calculations were limited by the slag-metal boundary zone. In the calculations the theories of molecular and ion structure were applied to the slag which allowed to predict non-metal inclusions in the weld metal. A range of models is currently used for calculations. They include models which connect chemical composition of the weld metal and composition of the slag by means of empiric equations [7-9] and multilevel regression combined polynomic equations [10].

At present time there are no methods of calculation of gas phase composition known. On the other hand, there is no doubt that oxides contained in the flux are intensively vaporized and often sublimate under the welding arc heat. As a result, the gas phase composition differs from the original one due to oxide content, the oxides are transferred to the gas phase directly. This fact makes it possible not to take into account the liquid phase. For the further calculation of their thermal dissociation principles of equilibrium thermodynamics of gaseous compounds are used. Thermal dissociation of gaseous oxides under the arc temperature in the front section of the welding pool is run in 
forward direction and is turned into recombination behind the arc. This is the exact moment of gas phase formation during the SAW.

Every oxide contained in the welding flux has its own parameters of thermal dissociation. They can be defined by means of chemical thermodynamics according to characteristic thermo dynamical functions of the original components and of the reaction products. In this case the main task is to develop an adequate method of calculation of the process of dissociation of the oxides contained in the welding flux during the welding process.

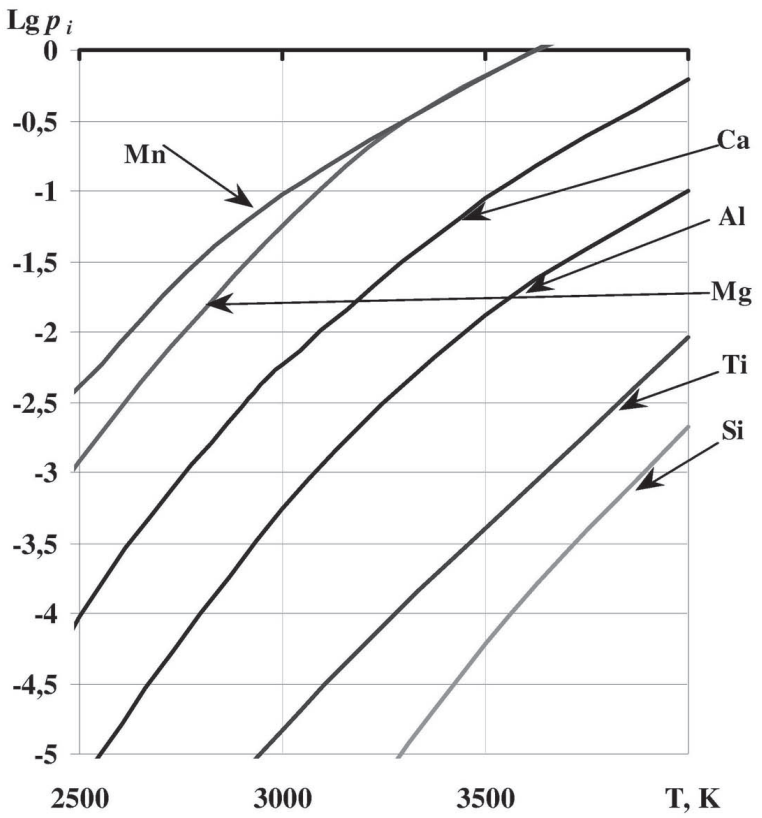

\section{Methods of calculation of thermal dissociation of oxides}

The process of thermal dissociation of oxides is run under heating. As a result, a gaseous mixture is formed which meets the case of equilibrium concentrations of condensed and gaseous phases $[6,11]$. In arc welding the concentrated heating source is present in the reaction zone, its temperature exceeding $6000 \mathrm{~K}$, which causes the processes mentioned to run in a different way. The fullest description of methods of calculation of thermal dissociation processes is given in the publications covering

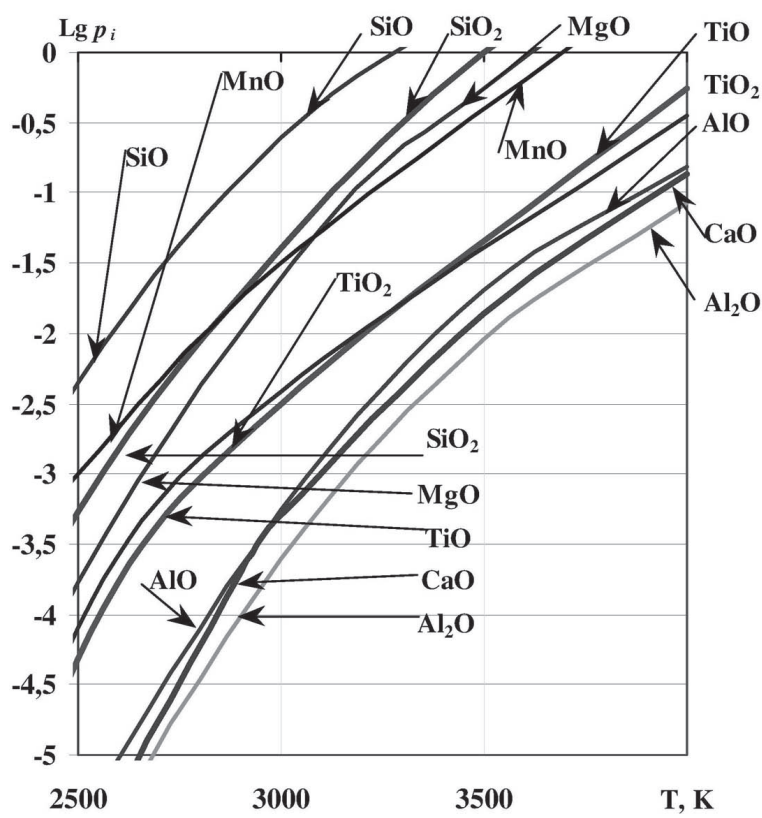

Figure 1. Patrtial pressure values of reaction products in thermal dissociation of $\mathrm{SiO}_{2} ; \mathrm{Al}_{2} \mathrm{O}_{3} ; \mathrm{CaO} ; \mathrm{MgO} ; \mathrm{TiO}_{2} ; \mathrm{MnO}$ oxides (according to data presented in [15])
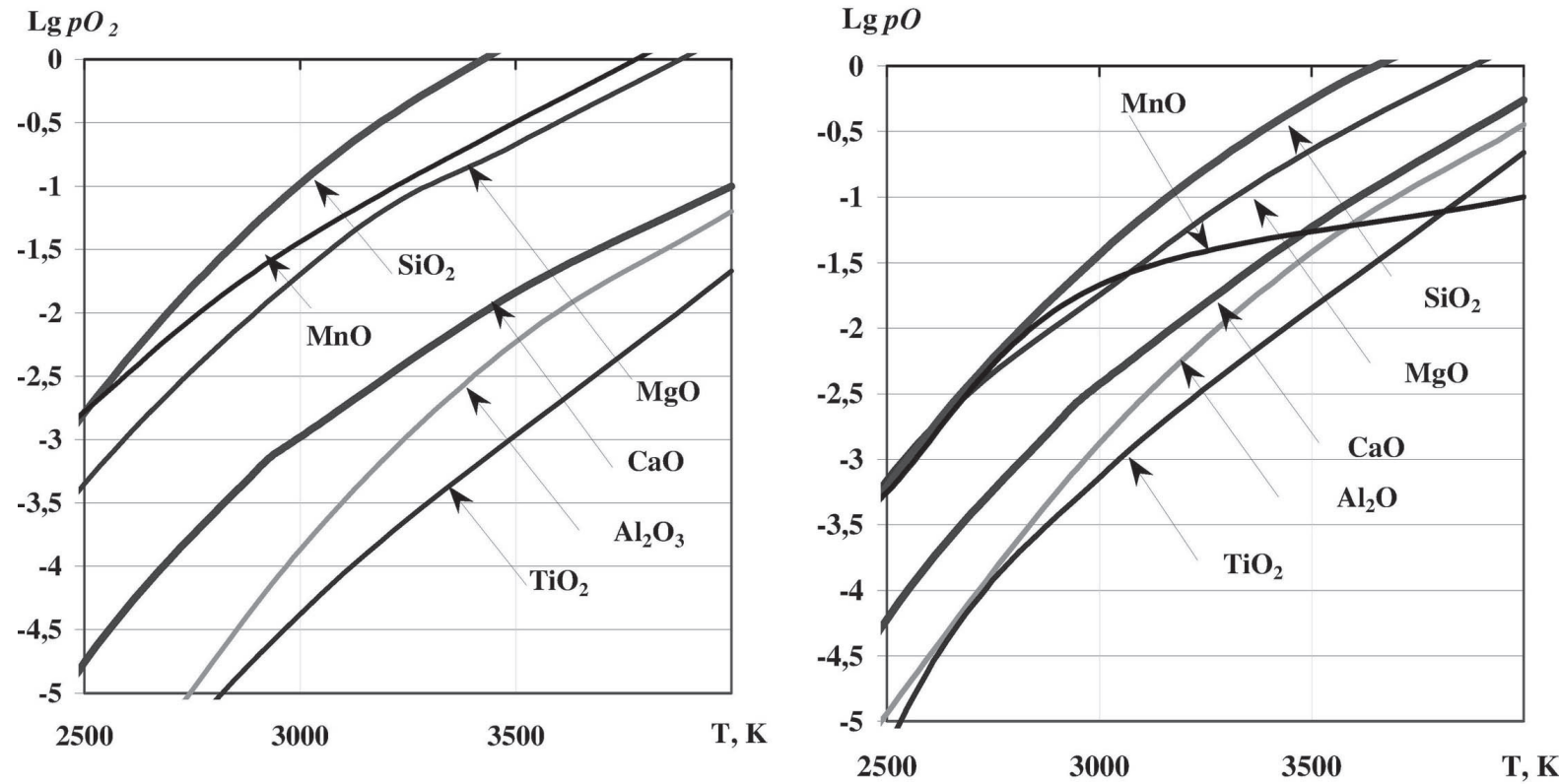

Figure 2. Patrtial pressure values of atomic and molecular oxygen in thermal dissociation of $\mathrm{SiO}_{2} ; \mathrm{Al}_{2} \mathrm{O}_{3} ; \mathrm{CaO} ; \mathrm{MgO} ; \mathrm{TiO}_{2} ; \mathrm{MnO}$ oxides (according to data presented in [15]) 
theory of metallurgical processes [11-15]. These processes are analysed one-sidedly: it is considered that as a result of thermal dissociation of lower oxides the reaction products contain the element itself (in the original state) and molecules of oxygen (rarely - oxygen in atomic state). When the oxide appears to be a result of reaction between solid or molten metal and oxygen the equilibrium constant includes only one parameter - oxygen partial pressure which is considered to be the oxide dissociation pressure (dissociation tension). More reasonable approach is presented in [14], where the oxide dissociation into metal and gas is analysed taking into account equilibrium between molten metal and gas.

The method developed by I. Kulikov allows to predict if a new condensed phase is formed as a result of thermal dissociation of chemical compound. The method resulted in calculation of partial pressure of components of the condensed oxide - system of gaseous components that includes oxygen, intermediate oxides and metals. In this method the reactions of dissociation are considered to run in parallel. The analysis of results of calculations according to method [15] has shown that in dissociation every oxide provides its own composition of gaseous phase (see Fig. 1, 2). These results qualitatively respond the real state in the range of temperature under study.

The principle of reactions being parallel, on which this calculation method is based, makes it impossible to take into account the further dissociation of gaseous oxides being products of the first reaction under temperature rise. As a result the partial pressure of metals, gaseous oxides, molecular and atomic oxygen gradually increases as the temperature rises. Still it is obvious that the temperature rise should result in their following partial dissociation, but this process isn't included into the I. Kulikov's method. If the temperature value is higher then $3250-3500$ $\mathrm{K}$, the partial pressure of gaseous oxides exceeds its highest possible value and the method becomes inadequate. The same situation refers the molecular oxygen, for which reaction of its generation should be analysed in parallel with its dissociation.

\section{Peculiarities of thermal dissociation of oxides during SAW process}

In SAW partial pressure of oxygen in the oxide-metal-oxygen system is defined with the assumption that both oxide and metal are in condensed state and the other components are formed as a result of vaporization processes. In this case none of the methods mentioned above is applicable due to the fact that in arc welding the processes of direct vaporization substantially define the quantitative composition of the gas phase components. The oxides contained in the flux sublimate under the arc energy, turn into gaseous state with further thermal dissociation in this state. The dissociation process turns into recombination when the temperature decreases.

The effect of arc on the metal in SAW process isn't uniform. Greater part of the arc energy is applied to the front of the reaction zone where it is absorbed by materials melting and vaporizing. They traverse the arc plasma and its border zones and as a result the gas phase is formed with the arc in its front section. Behind the arc, in the 'tail' section of the reaction zone the overheated gas-vapor mixture starts to cool down. The chemical processes which can be considered to be recombination (reverse to dissociation) ones are run. If the reactions run in the arc plasma are not taken into account $[2,4,9,16]$ and the zone to be analyzed is limited by the overheated gas-vapor mixture behind the arc, then all the reactions to be described will be those of formation of various gaseous compounds from gaseous components. As a result estimated values of partial pressure of gaseous components will be defined.

The main task on the first stage of gas phase analysis is development of the method of calculation of thermal dissociation of oxides in gaseous state.

\section{The method of settlement of dissociation of gaseous oxides of $\mathrm{MeO}, \mathrm{MeO}_{2}, \mathrm{Me}_{2} \mathrm{O}_{3}$ types}

To define the gaseous mixture composition the models are made describing the processes run under heating. The combined reactions are chosen on basis of data about qualitative composition of the mixture to be analyzed. The temperature rise leads to increase of the number of reactions in the gaseous state. These data can be obtained as a result of thermo dynamical analysis of all possible reaction of thermal dissociation of oxides in the gaseous state. It is reasonable to perform such analysis by the values of Gibbs energy taking into account the stoichiometric coefficients of reactions' components. Next the main reactions can be chosen on the priority basis, those describing the gaseous oxide dissociation. Every combined reaction can be operated as an independent thermo dynamical system with its own working formulas for estimation of roots of non-linear equations. Equilibrium of the reactions in such system is characterized by the equilibrium constant. The definition of gas phase composition requires a solution of non-linear combined equations and is usually made on PC. The most important and critical step of the gas phase composition estimation is the choice of the reactions. The limit temperature values for analysis were chosen equal to the gas phase gradient, which is limited by the temperature of boundaries of the arc (approximately $6000 \mathrm{~K}$ ) and molten slag (1400 K).

The process of thermal dissociation of gaseous compounds is characterized by the degree of dissociation $x$ and equilibrium constant of the reaction. The last can be calculated on the basis of the Van't Hoff equation and figured through the partial pressure values of reaction components. These values depend on the degree of thermal dissociation and the mole concentration of the components.

The method of settlement of thermal dissociation of gaseous oxides of $\mathrm{MeO}, \mathrm{MeO}_{2}, \mathrm{Me}_{2} \mathrm{O}_{3}$ types was developed taking into account reactions which are run simultaneously in parallel and in series. This method assumes formation of new (intermediate) gaseous compounds. The thermal dissociation is considered to take place in a homogeneous system. The decreasing of the temperature is assumed to cause reverse processes of recombination.

The final product of the method is a combined equation which describes relationship between equilibrium constant of the reaction and the degree of dissociation of the reaction 
components. The degrees of dissociation of all the reactions in the same system should be interrelated. The unknown values to be defined appear to be degrees of thermal dissociation of oxides and molecular oxygen for every reaction.

As an example, let's provide the calculation of the gas phase composition for the case of heating of gaseous oxides of metals. The temperature values will be limited to those which cause gas dissociation but don't cause its ionization (up to $6000 \mathrm{~K}$ ).

The oxide to be analyzed will be of $\mathrm{MeO}_{2}$ type (triatomic metal oxide) which is progressively dissociated. Taking into account interrelationship of all reactions, the number of moles of products of reactions of oxide dissociation should be equal to that of original materials of the reactions of further dissociation. Let's draw up the reactions assuming in the beginning there were 2 moles of the gaseous oxide:

$2 \mathrm{MeO}_{2}=2 \mathrm{MeO}+\mathrm{O}_{2}$

$2 \mathrm{MeO}=2 \mathrm{Me}+2 \mathrm{O}$

$\mathrm{O}_{2}=2 \mathrm{O}$

Under heating the gas partially dissociated with formation of $2\left(1-x_{1}\right)$ moles of $\mathrm{MeO}_{2}, 2\left(x_{1}-x_{1} x_{3}\right)$ moles of gaseous oxide $\mathrm{MeO}, 2 x_{1} x_{3}$ moles of gaseous metal Me, $\left(x_{1}-x_{1} x_{2}\right)$ moles of molecular oxygen $\mathrm{O}_{2}$ and $2\left(x_{1} x_{2}+x_{1} x_{3}\right)$ moles of atomic oxygen $\mathrm{O}$. The values $x_{1}, x_{2}$ and $x_{3}$ are the degrees of dissociation of the components of correspondent reaction, every one of them being a part of dissociated gas. The total number of moles in the mixture will be:

$\Sigma n=2+x_{1}+x_{1} x_{2}+2 x_{1} x_{3}$

The partial pressure of every component in the gas mixture is:

$$
\begin{aligned}
& N_{\mathrm{MeO}_{2}}=\frac{2\left(1-x_{1}\right)}{\sum n} \\
& N_{\mathrm{MeO}}=\frac{2\left(x_{1}-x_{1} x_{3}\right)}{\sum n} \\
& N_{O_{2}}=\frac{2\left(x_{1}-x_{1} x_{2}\right)}{\sum n} \\
& N_{O}=\frac{2\left(x_{1} x_{2}+x_{1} x_{3}\right)}{\sum n} \\
& N_{M e}=\frac{2 x_{1} x_{3}}{\sum n}
\end{aligned}
$$

The equilibrium constants of the reaction of parallel threestage dissociation will be described by the following analytical equations:
- reaction 1:

$$
K_{p}^{\prime}=\frac{x_{1}^{3} \cdot\left(1-x_{3}\right)^{2}\left(1-x_{2}\right)}{\left(1-x_{1}\right)^{2}\left(2+x_{1}+x_{1} x_{2}+2 x_{1} x_{3}\right)} ;
$$

- reaction 2:

$$
K_{p}^{\prime \prime}=\frac{4 x_{1}^{2} x_{3}^{2} \cdot\left(x_{2}+x_{3}\right)^{2}}{\left(1-x_{3}\right)^{2}\left(2+x_{1}+x_{1} x_{2}+2 x_{1} x_{3}\right)^{2}} ;
$$

- reaction 3:

$K_{p}^{\prime \prime \prime}=\frac{4 x_{1} \cdot\left(x_{2}+x_{3}\right)^{2}}{\left(1-x_{2}\right)\left(2+x_{1}+x_{1} x_{2}+2 x_{1} x_{3}\right)}$

The total mixture composition expressed in partial pressure values:

$$
p_{\mathrm{O}}+p_{\mathrm{M}}+p_{\mathrm{O}_{2}}+p_{\mathrm{MeO}}+p_{\mathrm{MeO}_{2}}=P
$$

For the $\mathrm{MeO}$ types of oxides the combined equation will be:

$$
\begin{aligned}
& K_{p}^{\prime}=\frac{x_{1}^{3} \cdot\left(1-x_{2}\right)}{\left(1-x_{1}\right)^{2}\left(2+x_{1}+x_{1} x_{2}\right)} \\
& K_{p}^{\prime \prime \prime}=\frac{4 x_{1} \cdot x_{2}^{2}}{\left(1-x_{2}\right)\left(2+x_{1}+x_{1} x_{2}\right)}
\end{aligned}
$$

For the $\mathrm{Me}_{2} \mathrm{O}_{3}$ types of oxides the combined reaction will be:

$$
\begin{aligned}
& 2 \mathrm{Me}_{2} \mathrm{O}_{3}=4 \mathrm{MeO}+\mathrm{O}_{2} \\
& 4 \mathrm{MeO}=4 \mathrm{Me}+4 \mathrm{O}
\end{aligned}
$$

$\mathrm{O}_{2}=2 \mathrm{O}$

The combined equation will be of the following form: - reaction 16 :

$$
K_{p}^{\prime}=\frac{64 x_{1}^{5} \cdot\left(1-x_{3}\right)^{4}\left(1-x_{2}\right)}{\left(1-x_{1}\right)^{2}\left(2+3 x_{1}+x_{1} x_{2}+2 x_{1} x_{3}\right)}
$$

- reaction 17 :

$$
K_{p}^{\prime \prime}=\frac{64 x_{1}^{4} x_{3}^{4} \cdot\left(x_{2}+x_{3}\right)^{4}}{\left(1-x_{3}\right)^{4}\left(2+3 x_{1}+x_{1} x_{2}+2 x_{1} x_{3}\right)^{4}}
$$

- reaction 18 :

$$
K_{p}^{\prime \prime \prime}=\frac{4 x_{1} \cdot\left(x_{2}+x_{3}\right)^{2}}{\left(1-x_{2}\right)\left(2+3 x_{1}+x_{1} x_{2}+2 x_{1} x_{3}\right)}
$$

The general equations obtained describe the process of parallel and series dissociation of molecules of $\mathrm{MeO}$ (14-15), $\mathrm{MeO}_{2}$ (1012) and $\mathrm{Me}_{2} \mathrm{O}_{3}$ (19-21) types taking into account temperature and individual values of thermo dynamical characteristic functions 
of elements and compounds taking part in the reactions. They allow to perform thermo dynamical analysis of thermal dissociation process for the oxides which are often included into the welding fluxes (such as $\mathrm{SiO}_{2}, \mathrm{TiO}_{2}, \mathrm{MnO}, \mathrm{CaO}, \mathrm{MgO}, \mathrm{FeO}$, $\left.\mathrm{Al}_{2} \mathrm{O}_{3}\right)$.

\section{The results of calculations of thermal dissociation process and their discussion}

The equations developed allow to calculate the gas phase composition for partial pressure values of the components and for their mole volume concentration values. As a result we obtain data about qualitative (partial pressure) and quantitative (mole volume concentration) composition of the gas phase. The first type of data is important for the general process analysis; the second may be used for evaluation of influence of the chemical composition of the welding flux on reactions in the welding zone and on the final chemical composition of the weld metal.

The results of calculations provided for the combined equations (14-15), (10-12) and (19-21) for $\mathrm{SiO}_{2}, \mathrm{TiO}_{2}, \mathrm{MnO}, \mathrm{CaO}, \mathrm{MgO}$, $\mathrm{FeO}, \mathrm{Al}_{2} \mathrm{O}_{3}$ oxides are shown on figures $3-9$. The values of thermo dynamical functions of the reactions' components were chosen from $[11,12,17]$ after their careful analysis and comparison. For all the oxides separate calculations were provided those describing their gasification from the initial state. The graph describing this process as if there were no condensation is shown on every figure with dotted line. In this way the temperature interval in which the calculations of oxide gasification should be carried out together with those of oxide condensation was defined.

$\mathrm{MeO}$ types of oxides.

During thermal dissociation of diatomic oxides the gas phase will include gaseous metal, atomic and molecular oxygen. During the process of cooling down these components will interact with formation of compounds corresponding to the equilibrium temperature. Let's analyze the calculated relations shown on Fig. 3-6.

Magnesium oxide $\mathrm{MgO}$

Mole fraction of the atomic oxygen in the gas mixture formed from the products of magnesium oxide dissociation will decrease at temperature around $4500 \mathrm{~K}$. After this value the mole fraction of gaseous magnesium will slightly increase due to redistribution of those of other mixture components. In the interval of 4500 to $2750 \mathrm{~K}$ atomic oxygen will turn into molecular one and in parallel it will take part in the reactions of gaseous magnesium oxide formation. After $2750 \mathrm{~K}$ the mole fraction of magnesium will sharply decrease. Maximum content of molecular oxygen in the gas phase approaches to $25 \%$. This is true for the temperature $2750 \mathrm{~K}$, thus we can assume that after this temperature reactions of magnesium oxide formation take place (see Fig. 3).

\section{Calcium oxide $\mathrm{CaO}$}

Mole fraction of the atomic oxygen in the gas mixture formed from the products of calcium oxide dissociation will decrease at temperature around $4500 \mathrm{~K}$ and at $2500 \mathrm{~K}$ it approaches to 0 . The mole fraction of gaseous calcium starts to decrease at $3500 \mathrm{~K}$ and almost disappears at $1500 \mathrm{~K}$. Maximum content of molecular oxygen in the gas phase approaches to $19 \%$ at

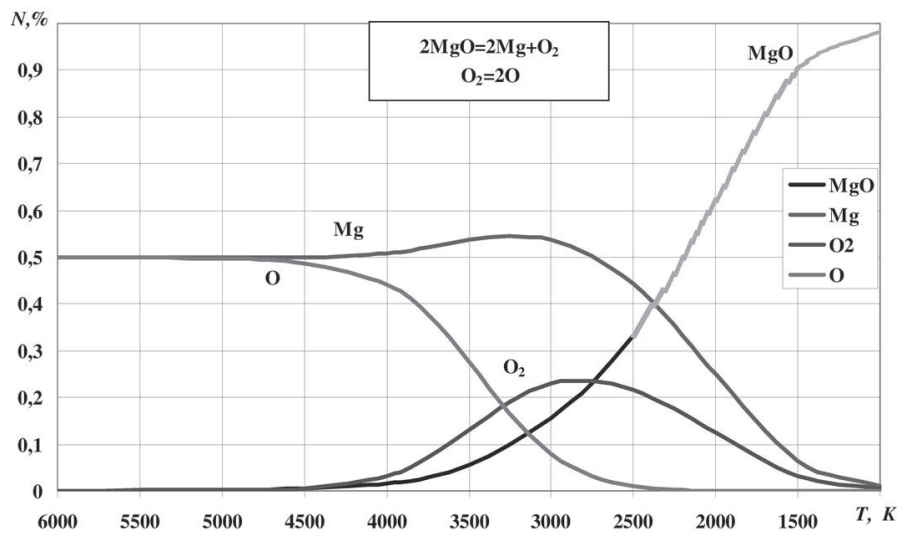

Fig. 3. Mole fraction values in the equilibrium gaseous mixture during the $\mathrm{MgO}$ oxide dissociation

temperature $3000 \mathrm{~K}$. While the temperature is higher then $3500 \mathrm{~K}$ the atomic oxygen turns into molecular one. When the temperature continues to decrease the atomic oxygen takes part in the reactions of gaseous calcium oxide formation. When the temperature is lower then $3000 \mathrm{~K}$ these reactions include the molecular oxygen. At temperature around $2500 \mathrm{~K}$ the calcium oxide starts to condensate (see Fig. 4).

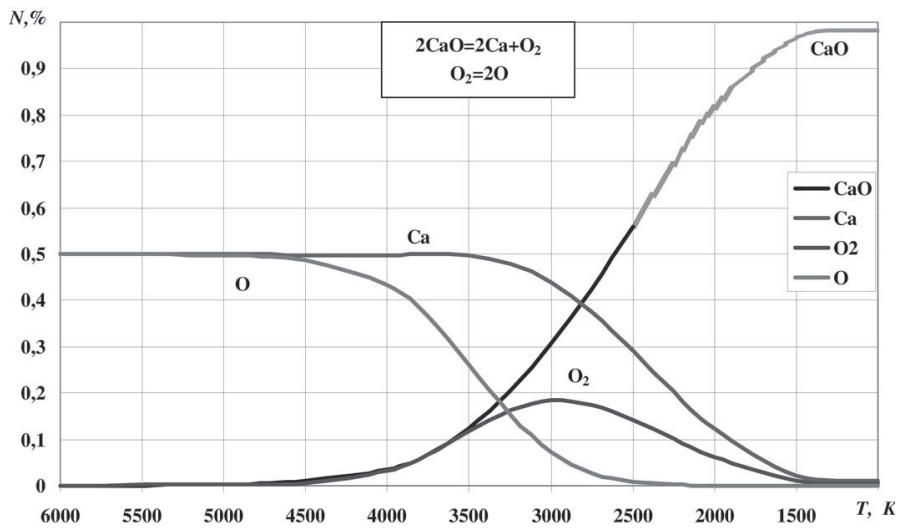

Fig. 4. Mole fraction values in the equilibrium gaseous mixture during the $\mathrm{CaO}$ oxide dissociation

\section{Iron oxide $\mathrm{FeO}$}

The mole fraction of the atomic oxygen and gaseous iron in the gaseous mixture formed during the $\mathrm{FeO}$ oxide cooling down start to decrease at temperature $6000 \mathrm{~K}$. This is due to formation of gaseous $\mathrm{FeO}$ oxide. Maximum content of the molecular oxygen in the mixture approaches $2.5 \%$ at $3700 \mathrm{~K}$. At temperature around $4250 \mathrm{~K}$ the iron oxide starts to condensate (see Fig. 5). It should be noted that in the analysis of reactions between the gaseous $\mathrm{FeO}$ oxide and the condensed components the possibility of formation of $\mathrm{Fe}_{2} \mathrm{O}_{3}$ and $\mathrm{Fe}_{3} \mathrm{O}_{4}$ oxides should be taken into account.

\section{Manganese oxide $\mathrm{MnO}$}

The mole fraction of the atomic oxygen during the $\mathrm{MnO}$ oxide dissociation starts to decrease at $4500 \mathrm{~K}$. This corresponds with formation of the molecular oxygen in the mixture. Its maximum concentration reaches $32 \%$ at temperature $2500 \mathrm{~K}$. This process is also followed by increasing of the mole fraction 


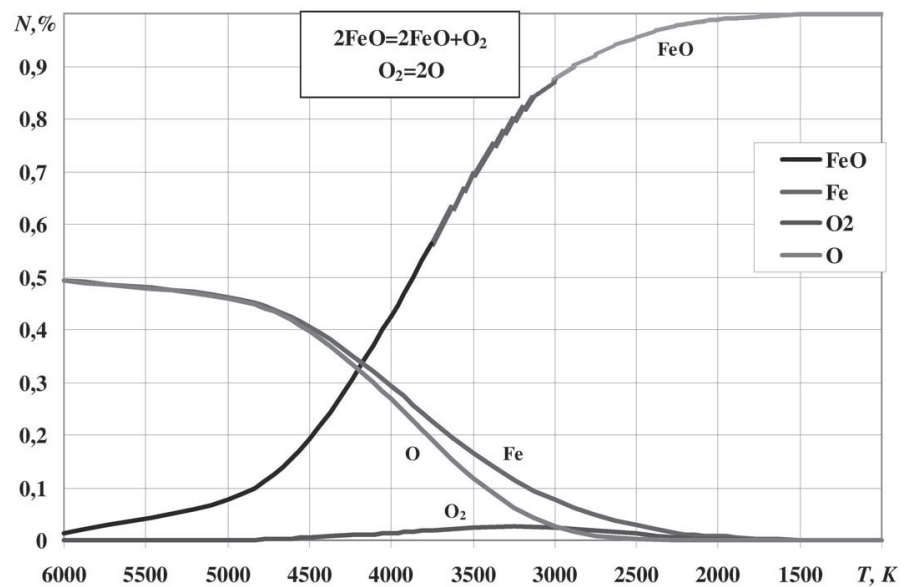

Fig. 5. Mole fraction values in the equilibrium gaseous mixture during the $\mathrm{FeO}$ oxide dissociation

of gaseous manganese being a result of redistribution of those of other mixture components. When temperature is lower then $2500 \mathrm{~K}$ the atomic oxygen disappears from the mixture. The mole fraction of manganese sharply decreases due to formation of gaseous manganese oxide (this process starts at $3500 \mathrm{~K}$ ). At temperature around $2000 \mathrm{~K}$ the manganese oxide starts to condensate (see Fig. 6).

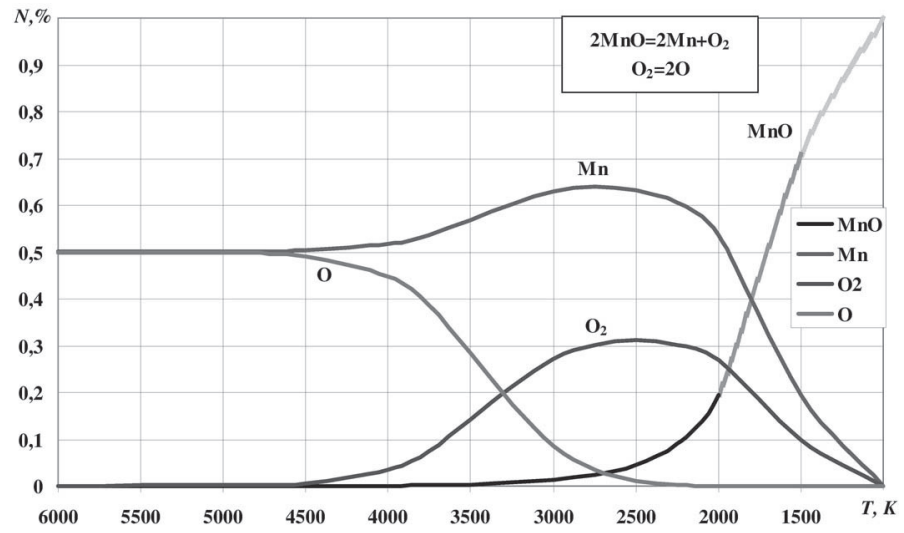

Fig. 6. Mole fraction values in the equilibrium gaseous mixture during the $\mathrm{MnO}$ oxide dissociation

\section{$\mathrm{MeO}_{2}$ types of oxides}

During the thermal dissociation of triatomic oxides the gaseous phase includes diatomic oxide of lower grade, gaseous metal being a part of the oxide, the atomic and molecular oxygen. During the cooling down these components interact and as a result some new elements are formed with their compound in the mixture corresponding to the equilibrium temperature. Let's analyze the calculated relations shown on Fig. 7-8.

Silicon oxide $\mathrm{SiO}_{2}$

The mole fraction of the atomic oxygen in the gaseous mixture during the silicon oxide dissociation starts to decrease at temperature $6000 \mathrm{~K}$ due to the lower oxide ( $\mathrm{SiO}$ ) formation. The curve bend at $4000 \mathrm{~K}$ can be explained by intensification of the molecular oxygen formation process. The maximum content of the molecular oxygen approaches to $28 \%$ at $2850 \mathrm{~K}$. The mole fraction of $\mathrm{SiO}$ oxide reaches its maximum of $60 \%$ at $3000 \mathrm{~K}$.
When the temperature continues to decrease it also decreases as the $\mathrm{SiO}_{2}$ oxide is forming.

The gaseous silicon practically disappears after $4500 \mathrm{~K}$, the atomic oxygen - after $2500 \mathrm{~K}$, the $\mathrm{SiO}$ oxide - after $1500 \mathrm{~K}$ (see Fig. 7). At the temperature $2500 \mathrm{~K}$ the gaseous silicon oxide starts to condensate.

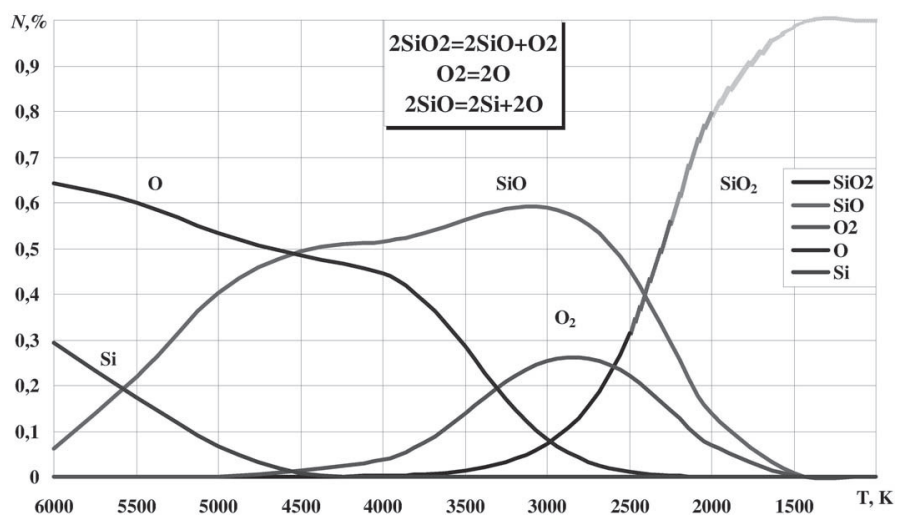

Fig. 7. Mole fraction values in the equilibrium gaseous mixture during the $\mathrm{SiO}_{2}$ oxide dissociation

Titanium oxide $\mathrm{TiO}_{2}$

Starting from $6000 \mathrm{~K}$ the mole fraction of the atomic oxygen and gaseous titanium in the mixture during the $\mathrm{TiO}_{2}$ dissociation gradually decrease. In parallel the gaseous $\mathrm{TiO}$ oxide is formed. Its concentration reaches its maximum of $44 \%$ at $3900 \mathrm{~K}$. The molecular oxygen appears in the mixture after $4500 \mathrm{~K}$, its maximum concentration being $5 \%$ at $3500 \mathrm{~K}$ (see Fig. 8). At the temperature $3600 \mathrm{~K}$ the gaseous titanium oxide starts to condensate.

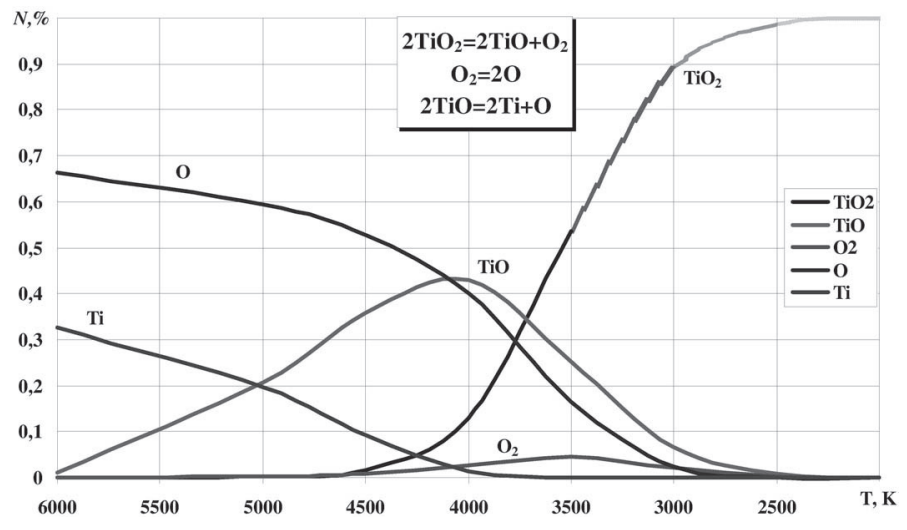

Fig. 8. Mole fraction values in the equilibrium gaseous mixture during the $\mathrm{TiO}_{2}$ oxide dissociation

\section{$\mathrm{Me}_{2} \mathrm{O}_{3}$ types of oxides}

The last oxide to be analyzed is aluminum oxide $\mathrm{Al}_{2} \mathrm{O}_{3}$. This compound is the hardest one due to its molecule structure which allows different gaseous compounds with oxygen to be formed. The gas phase aside from the $\mathrm{Al}_{2} \mathrm{O}_{3}$ oxide will contain other oxides: $\mathrm{AlO}, \mathrm{AlO}_{2}, \mathrm{Al}_{2} \mathrm{O}, \mathrm{Al}_{2} \mathrm{O}_{2}$. The thermo dynamical analysis has shown that in investigations of high-temperature gaseous mixtures it is possible to take into account $\mathrm{AlO}$ oxide only. 
Aluminum oxide $\mathrm{Al}_{2} \mathrm{O}_{3}$

Significant changes of the gas phase during the $\mathrm{Al}_{2} \mathrm{O}_{3}$ dissociation start from the temperature $4500 \mathrm{~K}$. The mole fraction of the atomic oxygen and gaseous aluminum decrease and those of the aluminum monoxide and molecular oxygen increase. They reach their maximums of $61 \%$ and $12.5 \%$ correspondingly at $3250 \mathrm{~K}$. When the temperature is lower then $3400 \mathrm{~K}$ the gaseous phase contains $\mathrm{Al}_{2} \mathrm{O}_{3}$. The atomic oxygen and aluminum disappear from the mixture after $2800 \mathrm{~K}$ (see Fig. 9). At this temperature the $\mathrm{Al}_{2} \mathrm{O}_{3}$ oxide starts to condensate.

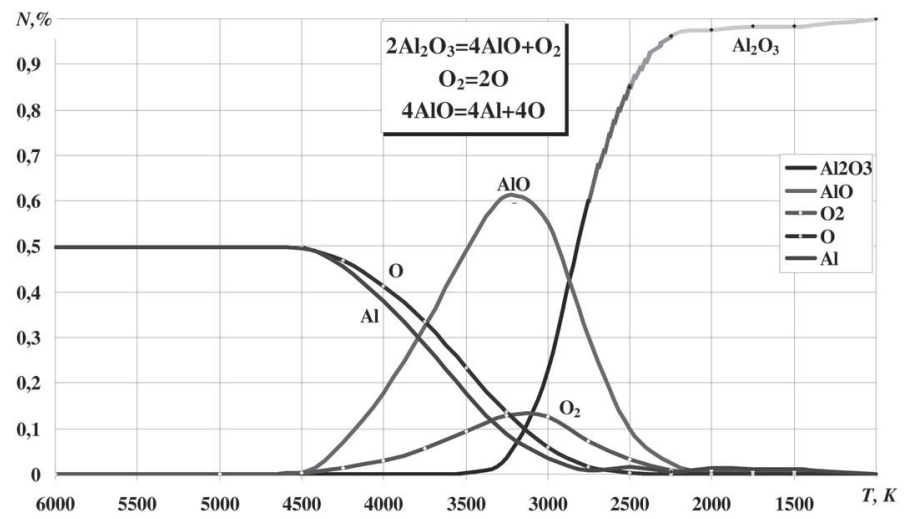

Fig. 9. Mole fraction values in the equilibrium gaseous mixture during the $\mathrm{Al}_{2} \mathrm{O}_{3}$ oxide dissociation

Some general conclusions can be made after the analysis of the results of calculations of gaseous mixtures during dissociation of different oxides:

1. Every oxide has its own dissociation mechanism which is directly related to its thermo dynamical characteristic functions.

2. The oxides can be arranged by the temperature of total dissociation as follows: $\mathrm{FeO}(6000 \mathrm{~K}), \mathrm{TiO}_{2}(4600 \mathrm{~K}), \mathrm{CaO}$, $\mathrm{MgO}(4500 \mathrm{~K}), \mathrm{SiO}_{2}(3700 \mathrm{~K}), \mathrm{MnO}, \mathrm{Al}_{2} \mathrm{O}_{3}(3500 \mathrm{~K})$.

3 . For the majority of the oxides analyzed $\left(\mathrm{SiO}_{2}, \mathrm{MnO}, \mathrm{CaO}\right.$, $\mathrm{MgO}, \mathrm{FeO}$ ) the atomic oxygen has a significant concentration in the gaseous mixture at temperature $2500 \mathrm{~K}$. For the $\mathrm{TiO}_{2}$ and $\mathrm{Al}_{2} \mathrm{O}_{3}$ oxides this temperature is higher - around $3000 \mathrm{~K}$.

4. The molecular oxygen appears in most of the gaseous mixtures after $4500 \mathrm{~K}$, the exception being $\mathrm{SiO}_{2}$ for which this temperature is $4700 \mathrm{~K}$. The oxides can be arranged by the lowest temperature of the molecular oxygen presence as follows: $\mathrm{MnO}$, $\mathrm{MgO}(1000 \mathrm{~K}), \mathrm{CaO}, \mathrm{SiO}_{2}(1500 \mathrm{~K}), \mathrm{FeO}, \mathrm{TiO}_{2}, \mathrm{Al}_{2} \mathrm{O}_{3}(2250 \mathrm{~K})$.

\section{Conclusions}

1. The analysis of methods of calculation of thermal dissociation process for oxides contained in the welding fluxes has shown that none of them allows to perform calculations for the specific conditions of SAW and welding deposition. It was shown that during welding the gas phase formation should be analysed as a process, reverse to dissociation, its initial components being gaseous compounds formed under the heat of the welding arc.

2 . The combined non-linear equations were developed to relate the degree of dissociation and equilibrium constant of the reactions taking into account the fact they run in parallel. These equations make it possible to perform calculations for all the oxides contained in the welding fluxes.

3. It was determined that every oxide has its own scheme of thermal dissociation which is determined by the thermo dynamical characteristic functions of the reaction components and by the combined equation which relate the degree of dissociation and the equilibrium constant.

4. All the oxides, even those of the same type, during their dissociation evolve the molecular and atomic oxygen to the gaseous mixture. The mole fraction values of the molecular and atomic oxygen depend on the temperature.

5. The data obtained for dissociation of gaseous oxides allow to perform numerical and qualitative analysis of the gaseous phase during the SAW process.

\section{References}

[1] E. O. PATON. Automated Electric Arc Welding // Moscow: Mashgiz, 1953. - $396 \mathrm{p}$.

[2] ZHDANOV L. A. Modern Ideas of Physical-Chemical model of SAW. Part 1. Existing schemes of SAW. Technological Systems, 2007, № 4, pp. 75-86. Part 2. Experimental Investigation of Reactive Zone During SAW. Technological Systems, 2008, № 1, pp. 38-45.

[3] ZHDANOV L. A., Kovalenko V. L. Ways of Exclusion of Subjective Factors and New Coplex Criterion for Evaluation of Stability of Electric Arc in Case of Welding Materials' Testing. Digest of the National Technical University of Ukraine «Kyiv Polytechnic Institute». Machine Engineering, 2011, № 61, pp. 52-56.

[4] A. A. BUKI .Simulation of Physical-Chemical Porcesses of Arc Welding // Moscow: Mashinostroyeniye, 1991. - 287 p.

[5] ZHDANOV L. A. Experimental and Theoretical Investigation of Effect of Droplet's Stage on Metallurgical processes in SAW and Submerged Arc Welding Deposition. Proceeding of the conference "Welding and Reated Processes and Technologies", Kyiv, 2011. - pp. 15-16.

[6] ZHDANOV L. A. Application of Equivalent Effective Temperature in Calculations of Mettalurgical Processes During SAW. Proceeding of the conference "Welding and Reated Processes and Technologies", Kyiv, 2012. - pp. 20-21.

[7] BORONENKOV B. N., Salamatov A. M. Calculated Evaluation of Cinetics of Interaction of Multicomponent Metal and Slag During SAW // Automated Welding, 1985, № 8, pp. 19-24

[8] H. THIER AND R. KILLING: Schweissen Schneiden, Sept. 1982, pp. E174-E176.

[9] MITRA U., Eagar T. W, Slag-metal reactions during welding: Part I. Evaluation and reassessment of existing theories. Metallurgical transactions. Vol. 22B. February 1991. pp. 61-71. Part II Theory. Metallurgical transactions. Vol. 22B. 73-s to 81-s, Part III. Verification of the theory. Metallurgical transactions. Vol. 22B February 1991. - pp. 83-101.

[10] P. KANJILAL, T. K. Pal S. K. Majumdar Prediction of Element Transfer in Submerged Arc Welding. Welding Journal/ 
№ 86, May 2007, pp. 135-146.

[11] KULIKOV I. S. Thermodynamics of Oxides // Moscow: Metallurgiya, 1986. - $342 \mathrm{p}$.

[12] KAZACHKOV E. A. Calculations in Theory of Metallurgical Processes // Moscow: Metallurgiya, 1988. - 288 p. [13] ROSTOVTSEV S. T. Theory of Metallurgical Processes. 2nd Edition // Moscow: Metallurgizdat., 1976 - 515 p.

[14] VOLSKIY A. N. Theory of Metallurgical Processes // Sergiyevskaya B. M. Moscow: Metallurgiya, 1968. - 344 p.

[15] KULIKOV I. S. Thermal Dissotiation of Chemical Compositions // Moscow: Metallurgiya, 1966. - $251 \mathrm{p}$.

[16] G. TYBUS, Farbige Zeitlupenaufnahmen zur Beobachtung des Schweißbades beim UP-Schweissen, "Schweissentechnik", Berlin, № 3, 1957.

[17] GLUSHKO V. P. Thermodynamical Properties of Individual Materials. B. R. // Moscow: Nauka, 1978. 